\title{
Analysis on the Auspicious Decoration Representation and Culture Implication of the Civilian House in Southern Fujian
}

\author{
Xiaocong $\mathrm{Hu}$ \\ Xiamen University of Technology \\ Xiamen, Fujian, China, 361024 \\ Xiaocong56@sohu.com
}

\begin{abstract}
Auspicious decoration is an important part of the traditional residential buildings in southern Fujian, reflecting the southern Fujian people a yearning for the pursuit of a better life, embodies the southern Fujian region unique history and culture, religious beliefs, national psychology and aesthetic taste. Through the systematic analysis of the types and manifestations of the auspicious decoration in the traditional houses of southern Fujian, this paper analyzes the internal and external motivations of its creation thoughts, and comprehensively understands the cultural connotation of the auspicious decoration of the traditional houses of southern Fujian, and plays an active role in protecting and inheriting the traditional culture of southern Fujian.
\end{abstract}

Keywords-Southern Fujian; Traditional Residential Building; Auspicious Decoration; Culture Implication

\section{INTRODUCTION}

The traditional residential buildings in southern Fujian are an important part of Fujian's regional architecture in the south of China. In the course of long historical development, the unique geographical environment has created a very national and regional architectural art. Auspicious decoration is a manifestation of folk culture in southern Fujian, is the people in the building beautify life, bless the life of the concrete performance, but also an important performance of traditional architectural decoration theme, and even can be said that the traditional building is "map must be intentional, Reflecting the background of the times, social mentality, national psychology and aesthetic taste, with a wide range of social awareness and geographical recognition. However, under the background of globalization, foreign culture has continuously influenced the inheritance of local culture. Modern architecture has gradually lost its regional characteristics in the tide of historical renewal. If the traditional architectural decoration forms which are rich in cultural heritage can not get enough attention, it is easy to be the impact of modern civilization fragmented. Therefore, the author sums up the types and manifestations of the auspicious decoration in the traditional houses of southern Fujian, analyzes the internal and external motivations of its creation and comprehensively, and comprehensively understands the cultural connotation of the auspicious decoration of the traditional houses of southern Fujian, so as to enhance the national self-confidence and build a modern harmonious society. Society has important significance [1].

\section{THE BASIC TYPES AND EXPRESSION METHODS OF AUSPICIOUS DECORATION OF TRADITIONAL CIVILIAN HOUSE IN SOUTHERN FUJIAN}

The formation of the traditional houses in southern Fujian was influenced by the culture of the Central Plains and influenced by the local geographical environment, climate and marine culture, and formed its own unique personality. In particular, the traditional living environment for the sea, to develop a southern Fujian people dare to take risks, the pursuit of wealth of human nature [2], architectural decoration craftsmanship, rich shape, reflecting the multi-cultural eclectic regional characteristics. Auspicious decoration mainly through wood carvings, brick and stone carving performance in the external walls, pillars, doors and windows and other architectural structure, it can be said that there must be auspicious decoration of the realm of connotation.

\section{A. The basic type of auspicious decoration}

Auspicious decoration as an integral part of folk culture, play a very important role in the daily life of the public, which is particularly evident in the Civilian House in Southern Fujian. Such as people in order to express pray for auspicious, avoid the bad things, often a variety of rich auspicious allegorical decoration in the various parts of the building, the subject of a wide range of animal species, plant flowers Fruit trees and auspicious gods, text objects, etc. In addition, due to the influence of a variety of religious culture in southern Fujian, auspicious decoration often appear with the religious meaning of the geometric pattern decoration theme. (1) Animal patterns from the Central China culture, residential often lions, elephants, phoenix, dragon, unicorn, bats and other auspicious relics and symbolic auspicious Bogut pattern organic combination, constitute auspicious peace blessing. (2) Fruits and flowers auspicious decoration, and traditional Chinese farming civilization are closely linked from the plant's homophonic or implication to express the love of life and the harmony between man and nature. (3) character decoration in accordance with the identity of the image of the identity can be divided into immortal figures and mortal figures, immortal

2015 Fujian Province Social Science Planning Youth Project "Study on the Dynamic Inheritance Strategy of Auspicious Decorative Culture in Fujian Traditional Residence” (FJ2015C093) 
figures on behalf of the gods, commonly used in the top of the wall, so that people look up to watch, mortal figures mainly reflect the traditional family education, Auspicious decoration reflects the specific historical period of social strata of real life, with folklore, life characteristics. (4) Ancient treasure is a favorite decorative theme, the traditional Tibetan houses are common vases, porcelain, religious treasures, bronze and other themes, the general combination of a rich picture, by a variety of artifacts, flowers meaning peace and good fortune desire. (5) text decoration is a more straightforward way of expression, the traditional Tibetan residential text decoration mainly contains: "longevity, wealth, blessing and Corning" and other auspicious connotation, reflecting the people's ideals and advocating a gentleman's style, A variety of materials, such as stone, brick, gray plastic, etc., in various forms, to increase the cultural charm of the building, and geometric patterns are more used in the decoration of the wall, the pattern of repeated rigorous and dynamic building facade, Reflecting the gorgeous style of Taiwanese. Such as the $¥$ pattern, tortoise pattern, ancient coin pattern, a symbol of wealth and continuous, future generations.

\section{B. The expression methods of Auspicious decoration}

The expression method of the auspicious decoration of the traditional Civilian houses in southern Fujian has a strong subjective color. After a long history, the formation of a relatively fixed program of ideographic methods, mainly symbolic, meaning, homophonic and so on. Symbolic means to use the specific image of things, to express abstract concepts and thoughts and feelings, but also traditional art and literature of the common approach [3]. The image of decorative arts is different from the reality of the prototype, is a symbolic symbol of artistic symbols, and is a unique art language, decorative symbolic culture is the background, to meet the practical function, according to aesthetic needs to create symbolic meaning, to arouse people's experience, memory and imagination. Symbolic techniques are more widely used in decorations. Minnan traditional houses in a symbolic way to express a specific theme, the object and people's good wishes linked. Farming period, the plant is an important resource for people to produce life, the use of plant decoration beautify life reflects people's love of life, people will naturally focus on some of the characteristics of plants, which symbolizes auspicious. Such as Quanzhou Chua's ancient residence of the wall to see the use of pine bamboo and magpie, plum and other themes match, a symbol of festive auspicious, family prosperity and noble character; Fig1 Jinjiang Wudian Civilian houses, Pomegranate under the roof of the house exposed seed, known as the "garlic hundred son" symbolizes the family descendants thriving Fig 2 homophonic is the life of animals, plants, artifacts as the prototype, the use of Chinese characters between the homonyms, close tone to replace the original intention, usually used vases, bats, magpies, plum and other elements , Such as Jinjiang Wu Dian traditional residential walls on the "peace like" decoration, the elephant and vase combination, as in the traditional Chinese culture is auspicious, the symbol of Safty and peace", meaning peace,Fig 3 Xiamen Haicang Yuanqian village residential "dragon Around the Incense Burner" window, the use of stone carving techniques to show the ancient culture of the gods, power, power; Fig 4

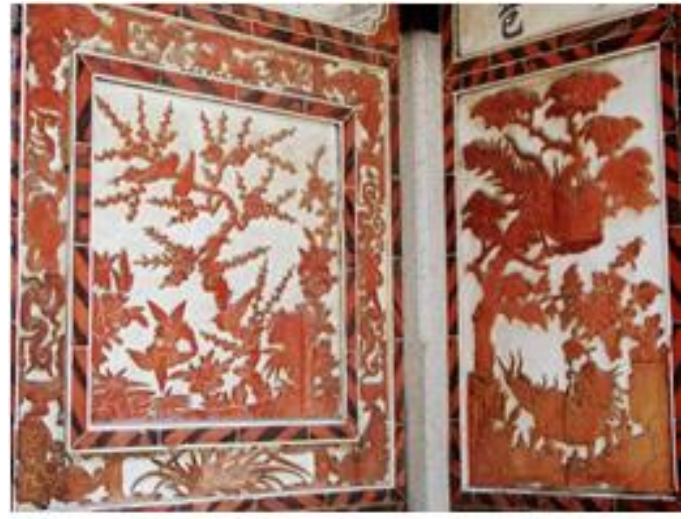

Fig. 1. Brick Carvings of Cai's Ancient House

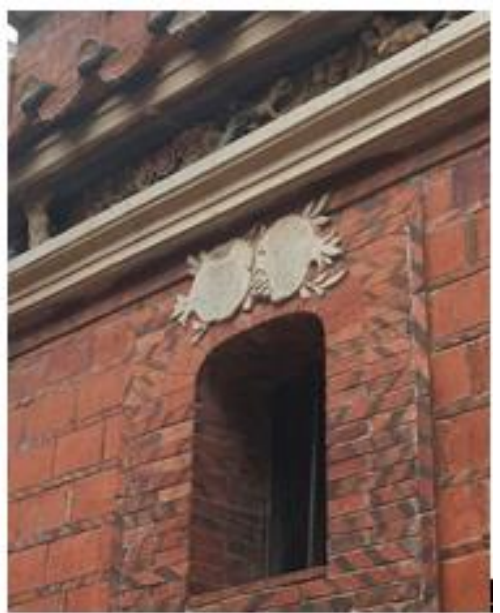

Fig. 2. Pomegranate decoration

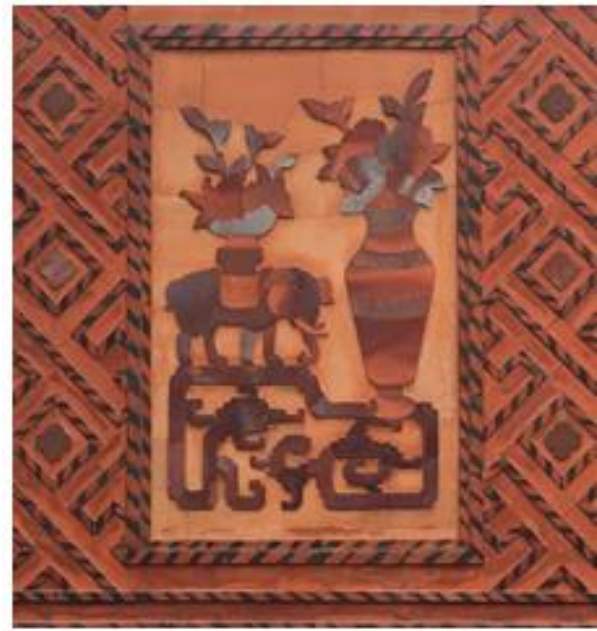

Fig. 3. "Safety and Auspicious" 


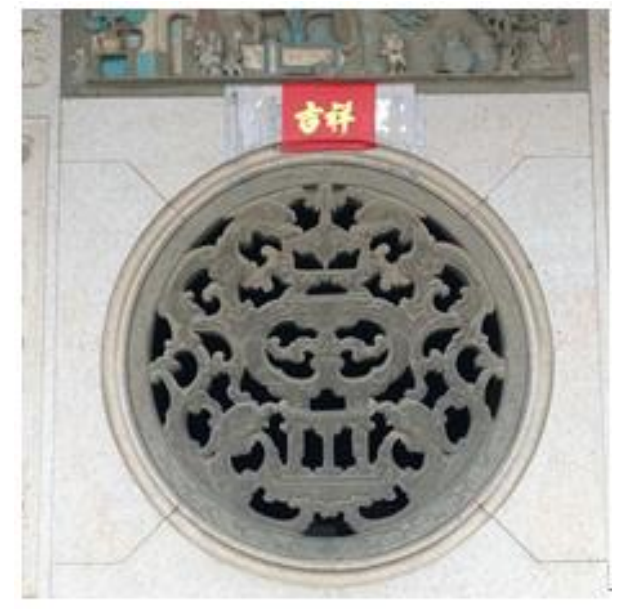

Fig. 4. Dragon Around the Incense Burner

\section{CULTURAL IMPLICATION OF AUSPICIOUS DECORATION IN SOUTHERN FUJIAN TRADITIONAL CIVILIAN HOUSE}

A nation is often a respect for the object, fear, worship and other common feelings, and in the collective generations, the performance of the cultural characteristics of the common psychological state, the formation and development of a nation is essential, is a long-term precipitation into a "meaningful form". Fujian traditional auspicious culture is the concrete manifestation of this collective psychology, which has become an important factor affecting the formation and development of the decorative arts in southern Fujian.

\section{A. Inherited the Central China culture, showing the integration of multi-cultural}

The southern Fujian region is the immigrant society in history, the Central China population migration for the region has brought a rich culture of the Central China, which directly affected the architectural decoration Inherited the Central China culture, such as the understanding of auspicious culture And the Central Plains culture is basically the same, but because of the impact of marine living environment, resulting in a number of strong regional auspicious cultural symbols, such as the "wind lion" of Jinmen Civilian House, sustenance of the Han folk, avoid disaster, blessing good desire. At the same time, the history of southern Fujian region is the starting point of "Maritime Silk Road", with the neighboring countries long-term exchanges and frequent exchanges, in the objective also promote the integration of Chinese and foreign cultures, so that southern Fujian residential decoration with obvious characteristics of overseas culture, Such as the southern Fujian residential brick, according to the textual research on the impact of the Islamic architectural culture.

The people of southern Fujian have open vision, trendy ideas and willing to accept the spirit of new things, after a long period of overseas life, refraction in the southern Fujian auspicious decoration to show two characteristics, first, decorative themes and manifestations of the original prototype of the Central Plains, Such as wall decoration details of the building figures, auspicious text, Begonia flowers, coins pattern, etc., usually in the form of brick, stone or cut sticky process to complete, so that the building facade rich changes; second, decorative gorgeous, color Rich, such as Quanzhou Yang A Miao residential, the building is almost concentrated in southern Fujian all the means of decoration, facade facade is the most exciting part: white stone wall, bluestone pillar and wall trim with decorative, red brick Veneer and cornice "Shuichedu" clay sculpture clever combination, constitute a bright color contrast, composed of gorgeous wall pattern, showing its wealthy style [4]

\section{B. Advocating respect for the culture of Immortal, to show the diversity of religious beliefs}

The strong ancestor worship in the southern part of the country and the worship of the Immortal in the region are the signs of the transformation of the immigrants from the memory of the Central Plains to the recognition of the new home of southern Fujian. First of all, the Han immigrants after hardships immigrated to Fujian, will often miss their homeland, so they will be in the architectural decoration imitation of the original residential decoration; Second, Confucianism, Buddhism, Taoism and trinity of religious beliefs have shown the diversity of the Central Plains culture. After the integration of the customs of the Minyue people, the concept of utilitarian belief makes the Minnan people face in the impact of foreign religious culture, with an inclusive, open attitude, the other religions are introduced to the southern Fujian folk belief system, with these beliefs As the center of the decorative culture, naturally also in a multi-coexistence model appeared in the southern Fujian architectural decoration. Such as Buddhist 叉 word patterns and artifacts are often decorated on the wall.

The Confucianism and Taoism have a close relationship with Confucianism and Taoism. For example, Confucianism emphasizes "self-cultivation" as the theme of access to the society, and often uses "pine, bamboo and plum" as the theme of conveying auspicious cultural ideas. Fig 5 in the ideal of life, Confucianism encourages the pursuit of reading and acting as the greatest wish of people. Under the influence of this kind of thought, the auspicious words such as "fish leaping over the dragon gate, Five sons get on the list, upgrade three levels" are artificially integrated into The Taoist ideology of the "blessing, longevity, health, Ning" like the pursuit of auspicious connotation, often materialized as Taoist characters, artifacts and related to the symbol of longevity animals; flowers and birds pattern decoration is Taoism advocating return to nature, The Concrete Embodiment of the Thought of Harmony between Human and Nature [5].

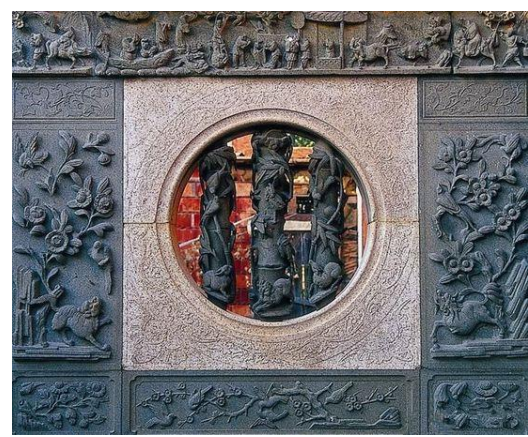

Fig. 5. Bamboo windows 


\section{Attention to business culture, show the gorgeous style of decoration}

The people of southern Fujian cultivated self-confidence and open up consciousness. The bad natural resources made them reluctant to stick to the agricultural production and the living environment. The value system of southern Fujian people was more material and the conditions of living were improved. The spirit of the pragmatic spirit, advocating commercial and industrial workers is also the external spirit of southern Fujian people; Min Yue culture in the light and light meaning, talk about reality, do not value the letter about the characteristics of the influential businessmen in southern Fujian; southern Fujian away from the Central China cultural area, traditional Confucian Cultural "despise businessmen" in Fujian is not dominated, southern Fujian area respected "business can get rich", "business is better than the handicraft and agriculture", the above together formed a concept of southern Fujian people in the heavy sense of profit As well as open and inclusive mentality. Therefore, southern Fujian people like to use gorgeous materials, decorative buildings, such as the facade wall will use the overall form of beauty and rich changes in the masonry walls, spell into different decorative patterns; building side of the gable is often decorated with clay sculpture color Bright graphics, such as use flower baskets to express increase population.

\section{Contemporary Cultural Value of Auspicious DECORATION IN TRADITIONAL SOUTHERN FUJIAN FOLK HOUSES}

The auspicious decoration of the southern Fujian houses is the crystallization of the collective wisdom of the traditional southern Fujian people. It is of artistic value, cultural value and social value. It is also an important part of the local culture of Minnan. In the highly developed globalization today, by the impact of international architectural style, urban and rural construction more and more consistent, the lack of local characteristics of the architectural decoration is difficult to reflect the characteristics of the city, while the traditional southern Fujian dwelling in modern cities in the living space is extremely limited, The architectural decoration of its attention is much less, therefore, the southern Fujian traditional building auspicious decoration should play today should be the contemporary value. On the one hand, the theoretical research value, the understanding of the auspicious decoration of the traditional houses in southern Fujian, that is, the understanding of the traditional culture of southern Fujian, which is conducive to the system combing the decorative culture of southern Fujian and explore the path of symbiosis with contemporary culture; the other hand, Whether the auspicious decoration of the traditional houses in southern Fujian can play a role in today's urban and rural construction can be combined with contemporary decorative culture. This is an important way to protect the traditional culture of southern Fujian. Only traditional building decoration, based on contemporary demand, Auspicious decoration organic integration into the modern building, in order to better inherit the southern Fujian regional culture.

\section{CONCLUSION}

Tsinghua University Professor Li Yanzu think: decoration need satisfy the requirements such as order, regularization, stylized and Idealization, change and beautify things, in line with human needs, and human aesthetic ideal unity and harmonious beauty of the form. southern Fujian traditional houses wide range of themes and content, colorful architectural color form, fantastic decorative patterns and with traditional Chinese cultural characteristics and the combination of living concepts, multi-dimensional creation of the living environment, a great extent to beautify the people's Vision and psychology, a profound highlight of the unique geographical culture of southern Fujian, compared to other provinces and cities in China's ancient buildings, very different, the research value is also quite rich. To study the cultural connotation and contemporary value of the auspicious decoration of the traditional houses in southern Fujian, it is to better understand and protect the traditions and explore the path between tradition and contemporary, so that modern people can fully understand the artistic charm of traditional decoration and protect this precious history Cultural heritage.

\section{REFERENCES}

[1] MaJun. Contemporary Cultural Value of Chinese Traditional Auspicious Decorative Art. [J].HuBei Social Sciences, 2012(5):105-108.J. Clerk Maxwell, A Treatise on Electricity and Magnetism, 3rd ed., vol. 2. Oxford: Clarendon, 1892, pp.68-73.

[2] CaoChunPing.Architecture of Southern Fujian.[M].Fujian People Press, 2008:16.

[3] ZhengHuiMing.Research on Architectural Decoration and Cultural Expression of the Traditional Dwellings in Southern Fujian.[D].China Central Academy of Fine Arts.2016:248-251.

[4] DaiZhiJian.Fujian dwellings. [M].BeiJing, China Construction Industry Press.2009:134

[5] ZhangXiMing.A brief discussion on the influence of Minnan spirit on the traditional folk houses in South Fujian -- the influence of the folk custom of South Fujian on the architectural style of Southern Fujian. [D].Tongji University.2009:9. 